УДК 532.529:663.14. 033: 663.143.2

\title{
ОСОБЕННОСТИ ГИДРОДИНАМИЧЕСКОЙ ОБРАБОТКИ ПИТАТЕЛЬНЫХ СРЕД В РОТОРНО-ПУЛЬСАЦИОННОМ АППАРАТЕ
}

\author{
Ободович А.Н. ${ }^{1}$, д.т.н., Мудрак Т.Е. ${ }^{2}$ к.т.н., Сидоренко В.В. ${ }^{1}$ \\ ${ }^{1}$ Институт технической теплофизики НАН Украины, ул. Желябова, 2а, Киев, 03680, Украина \\ ${ }^{2}$ Национальный университет пищевых технологий МОН Украинь, ул. Владимирская, 68,
} Киев-33, 01601, Украина

У статті представлені результати досліджень по експериментальному визначенню гідродинамічних характеристик роботи роторнопульсаційного апарату на поживних середовищах для культивування дріжджів.
В статье представлены результаты исследований по экспериментальному определению гидродинамических характеристик работы роторно-пульсационного аппарата на питательных средах для культивирования дрожжей.

Библ. 5, рис. 7.

Ключевые слова аэрация, расход, напор, потребляемая мощность, роторно-пульсационный апарат.

Большинство процессов в биотехнологии связаны с явлением массопередачи. В частности, массопередача имеет место в процессах аэрации, абсорбции, сушки, адсорбции, кристаллизации и др. Интенсификация этих процессов как в направлении их ускорения, так и уменьшения требуемой для их осуществления энергии позволит сделать производство более рентабельным.

Процесс аэрации или, точнее оксигенации [1], используется в первую очередь в отраслях, связанных с промышленным культивированием живых существ (аэробов), в основе метаболизма которых лежит окисление углеводов. Кроме того, молекулярный кислород может включаться в процессы конструктивного метаболизма клеток, обеспечивая синтез ими некоторых соединений [2]. В частности, одним из основных критериев успешного культивирования дрожжей расы Saccharomyces cerevisiae, помимо выведения новых высокопродуктивных видов, подбора питательных сред, высоко-стерильных условий культивирования, является эффективная аэрация культуральной жидкости. От степени аэрации напрямую зависят темпы увеличения биомассы дрожжей при их выращивании. Применяемые с этой целью в промышленности аппараты, как правило, представляют собой барботеры [3], принцип действия которых состоит в подаче воздуха под высоким давлением через систему перфорированных кожухов различной конструкции в донную часть дрожжерастильных емкостей. Эффект аэрации заключается в том, что образующиеся в отверстиях пузырьки воздуха, поднимаясь вверх, отдают имеющийся растворённый в газовой фазе кислород в культуральную жидкость. Кроме того, от клетки во внешнюю среду выводятся продукты клеточного метаболизма. При неоспоримых преимуществах этих аппаратов, им присущи серьезные недостатки, к которым, в первую очередь относится низкая скорость растворения кислорода.

С целью интенсификации процесса массообмена при аэрации культуральных жидкостей в Институте технической теплофизики НАНУ была создана опытно-промышленная установка по культивированию микроорганизмов (ферментёр), в основу работы которой положен принцип дискретно-импульсного ввода энергии (ДИВЭ), описание аппаратурно-технологической схемы которой представлено в работе [4].

Установка состоит из бункера с крышкой, тихоходной мешалки с приводом. Мешалка применяется в режимах культивирования, сочетающих в себе периоды активной обработки куль- 
туральной жидкости с периодами “покоя”, когда к дрожжевым клеткам импульсное воздействие не прикладывается. В этом случае перекрывается заслонка в донной части бункера. Кроме того, эта заслонка служит регулятором подачи жидкости через всасывающий трубопровод. С целью создания определённых температурных условий культивирования бункер снабжён охлаждающей рубашкой. Загрузка питательной среды и бактериальной закваски, а также отвод газообразных продуктов метаболизма производится через верхнюю крышку бункера.

Отличительной особенностью установки является роторно-пульсационный аппарат (РПА), использующийся в данной установке в качестве аэратора, диспергатора и смесителя, который состоит из корпуса с входным и выходным патрубками, системы трубопроводов для рециркуляции или вывода готовой продукции, горизонтального роторного узла, состоящего из двух роторов и одного статора, размещающихся в одном неподвижном стакане. На цилиндрических поверхностях статора и роторов выполнены 60 сквозных продольных прорезей. Радиальный зазор меж- ду рабочими органами ротор - статор - ротор $150 \ldots 300$ мкм.

Воздух, являющийся источником кислорода, за счёт эффекта Вентури [5], поступает через воздуховод во всасывающий трубопровод. В рабочей зоне РПА за счёт воздействия механизмов ДИВЭ, культуральная жидкость насыщается растворённым кислородом и далее через рециркуляционный трубопровод снова подаётся в бункер.

Полученные данные свидетельствуют о том, что с ростом скорости вращения роторов растёт значение расхода жидкости и, как следствие, увеличивается подача воздуха на аэрацию. Однако, с ростом скорости вращения, растет потребляемая мощность. Таким образом, режимом формирования водовоздушной смеси, обеспечивающей максимальную подачу воздуха и в то же время позволяющем работать в течение длительного времени без перегрузок, является режим работы при частоте 47,75 об/с и расходе водовоздушной смеси $-2,18$ л/с.

В общем случае, влияние подачи воздуха в обрабатываемую среду отображено на рис. 3 5 , как функции от угловой скорости роторов.

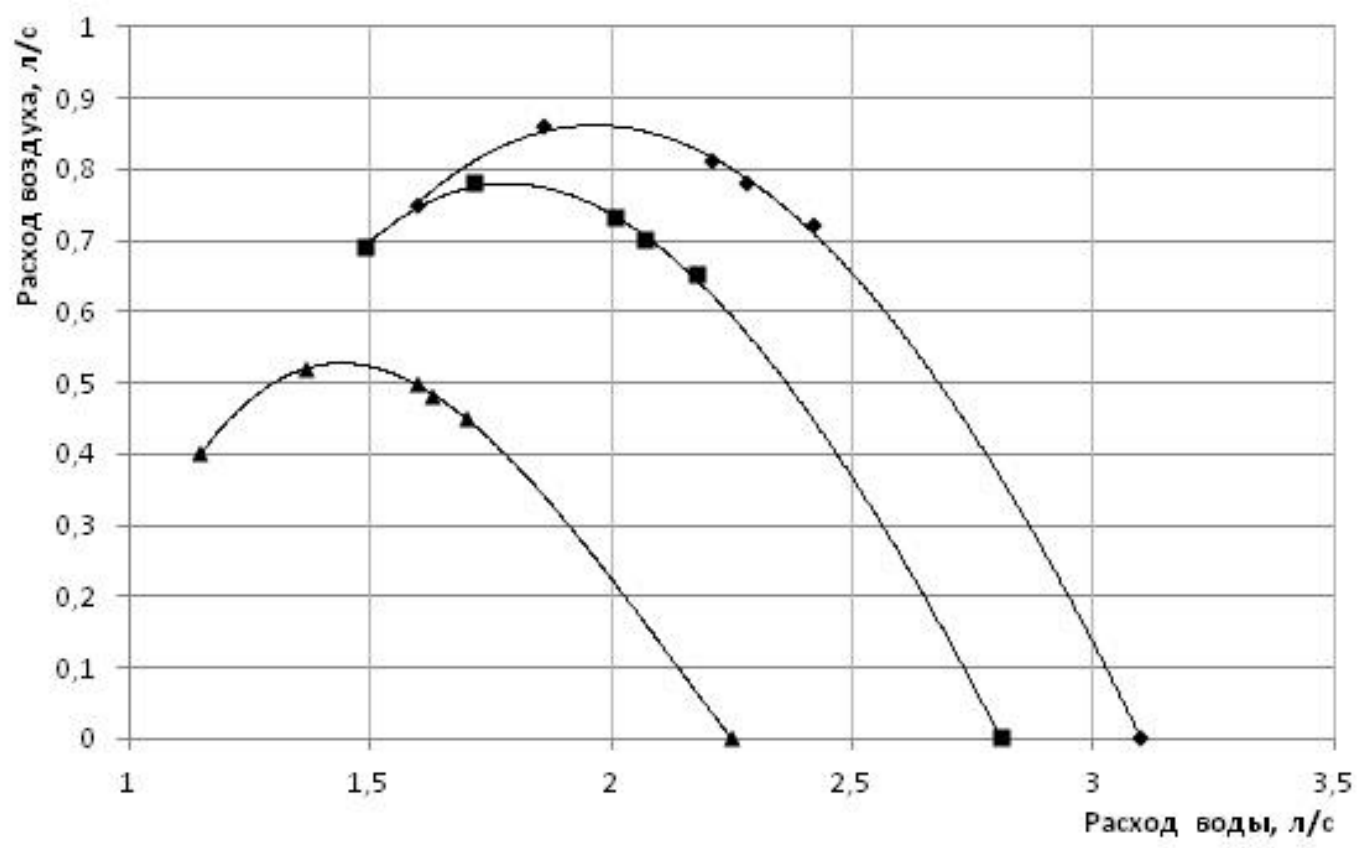

Рис. 1. Зависимость подачи воздуха от расхода жсидкости при различной угловой скорости роторов: $\triangle-38,2$ об/c, $\mathbf{-}-47,75$ об/c, - 52,52 об/c. 


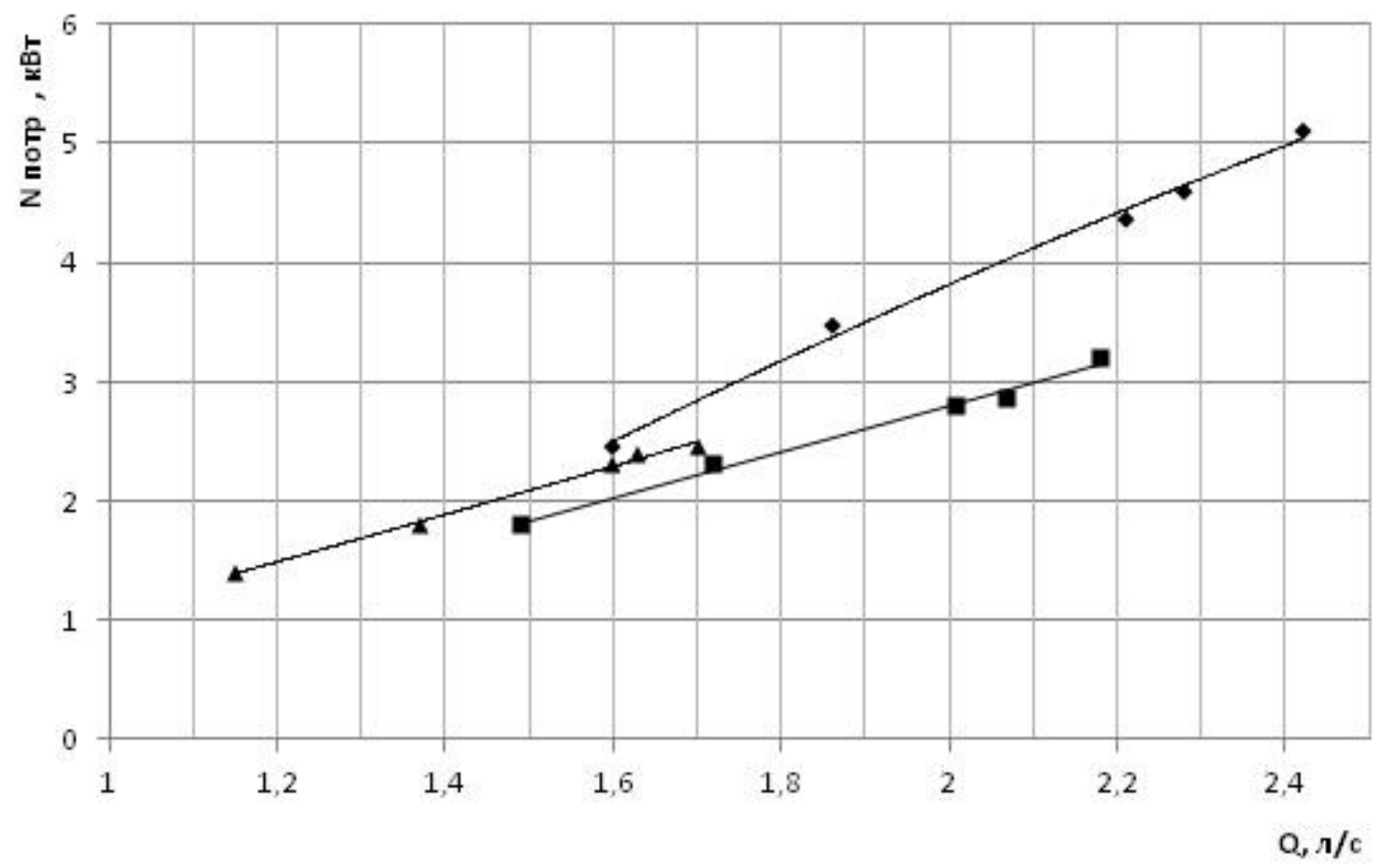

Рис. 2. Зависимость потребляемой мощности от расхода энидкости при различной угловой скорости роторов: $\triangle-38,2$ об/c; - $-47,75$ об/c; - 52,52 об/c.

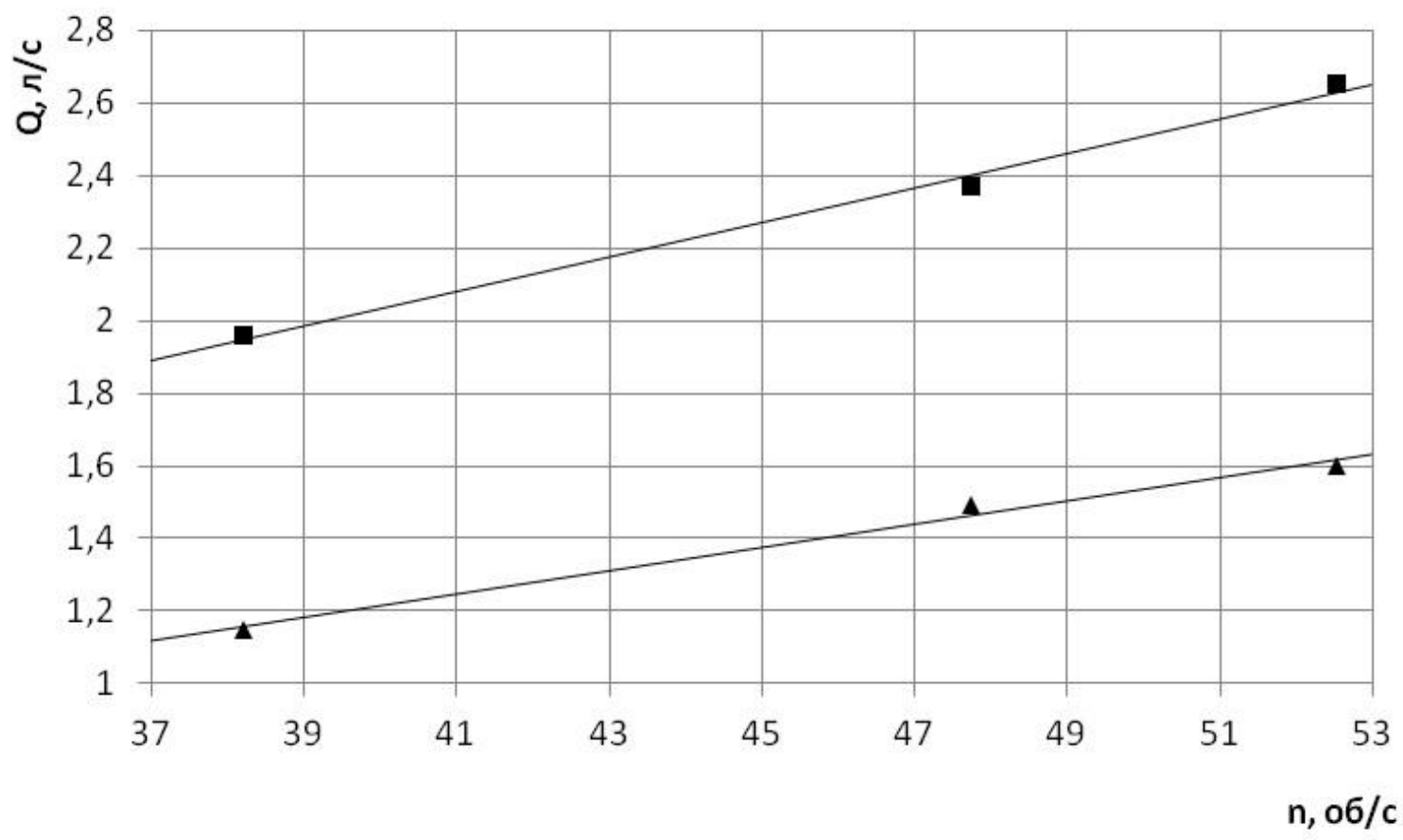

Рис. 3. Зависимость расхода жникости от угловой скорости врацения роторов: - - без подачи воздуха, $\Delta$ - с подачей воздуха. 


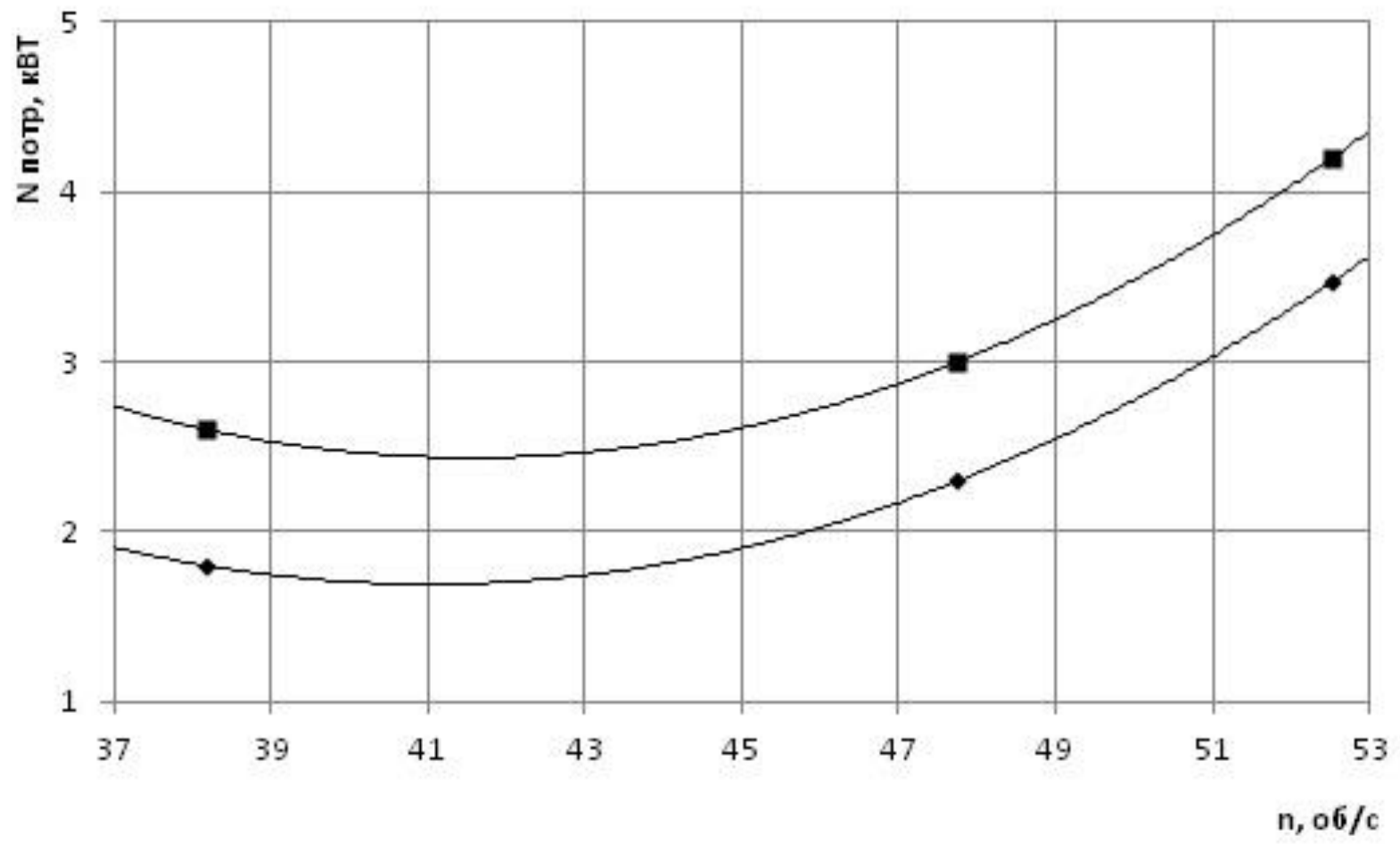

Рис. 4. Зависимость потребляемой мощности от угловой скорости вращения роторов. 1- без подачи воздуха, 2 - с подачей воздуха.

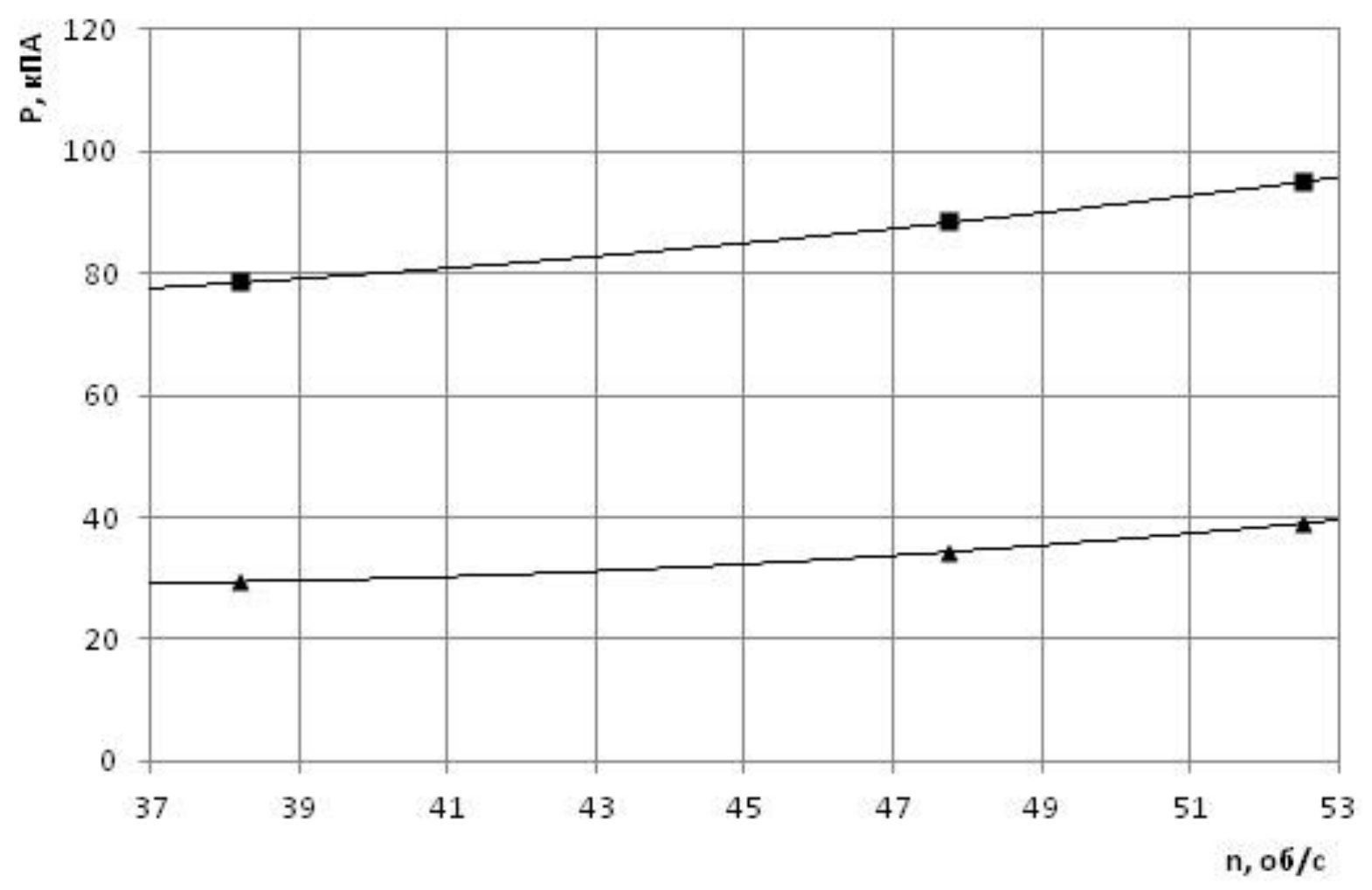

Рис. 5. Зависимость давления на выходе РПА от угловой скорости вращения роторов: - без подачи воздуха, А - с подачей воздуха. 


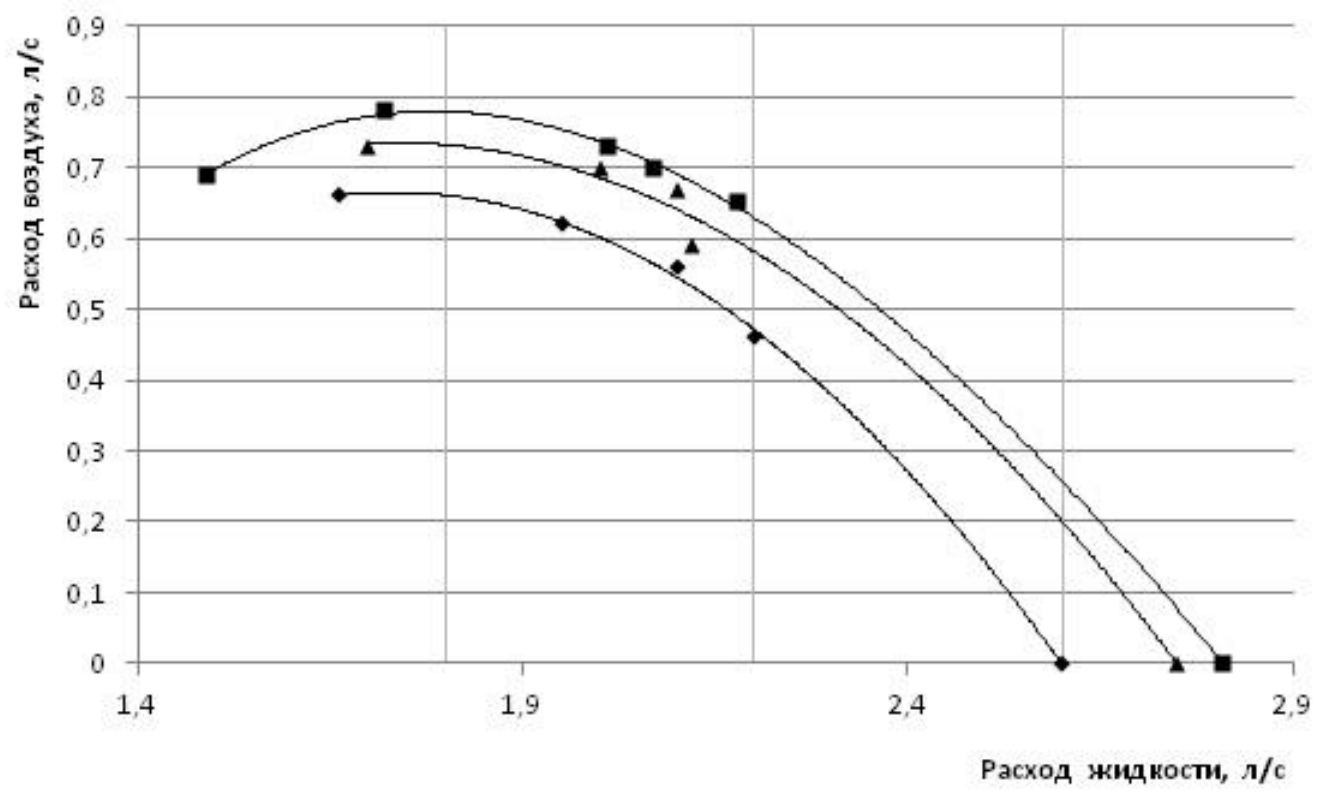

Рис. 6. Зависимость подачи воздуха от расхода жедкости при различном содержании СВ:

- - вода; $\triangle-5 \%$; $-10 \%$.

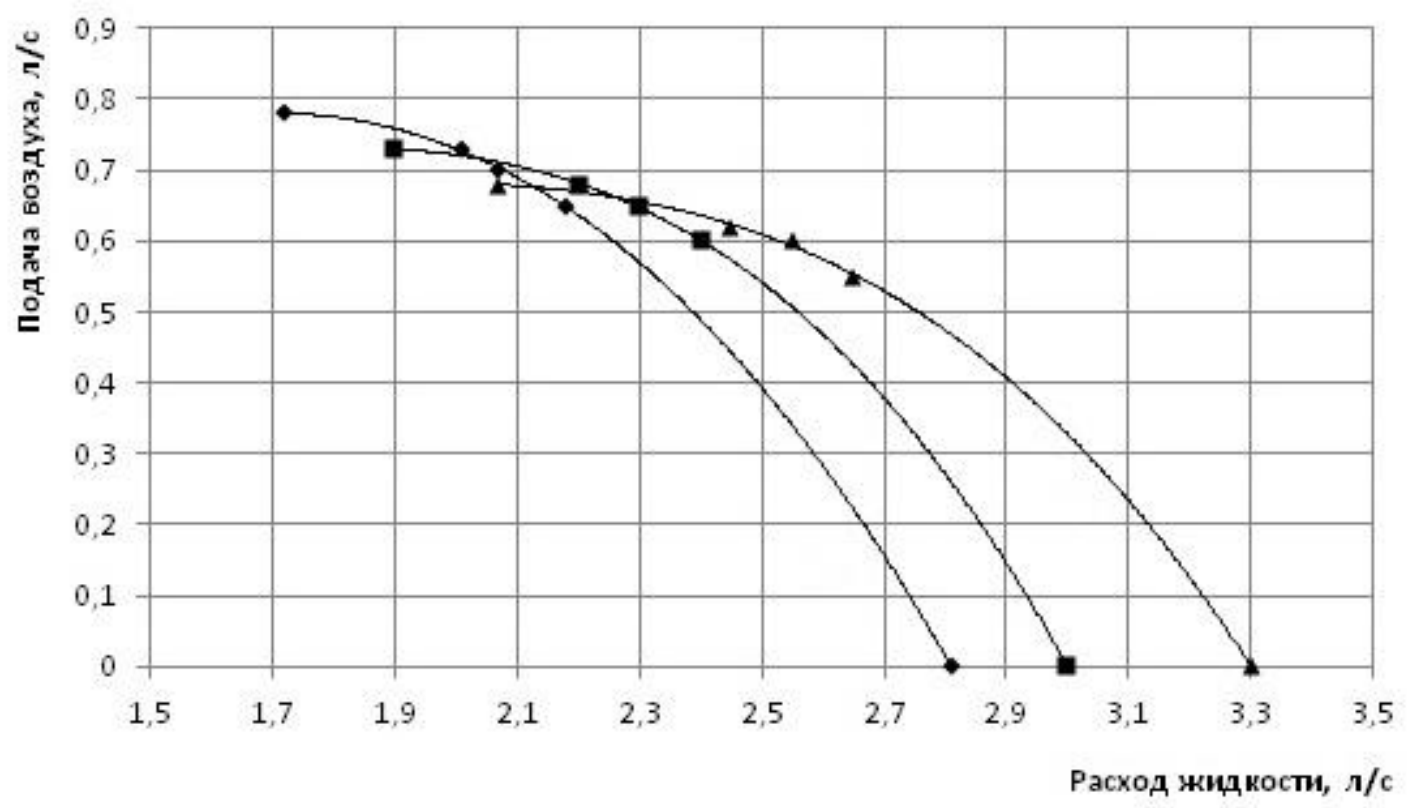

Рис. 7. Зависимость подачи воздуха от расхода жеидкости при различных зазорах между статором и роторами . - 150 мкм; - 200 мкм; А - 300 мкм.

Дальнейшие исследования проводились на модельных средах, представляющих собой водные растворы сахара и питательных солей с различным содержанием сухих веществ (СВ) при $\mathrm{pH}=5,0$. Температура обработки $28{ }^{\circ} \mathrm{C}$. Обработка велась при скорости вращения роторов 47,75 об/с. Результаты исследований представлены на рис. 6. 
Из графиков видно, что с увеличением концентрации сухих веществ в смеси расход жидкости, а значит - подача воздуха уменьшаются, что, очевидно, связано с увеличением вязкости обрабатываемой жидкости. Однако следует отметить, что повышение вязкости ведёт к весьма незначительному увеличению потребляемой мощности.

Помимо физических свойств среды, на обработку влияет толщина зазоров между роторами и статором. Влияние этого параметра отображено на рис. 7. Межцилиндровый зазор менялся за счёт замены роторно-статорных пар.

Полученные данные свидетельствуют о том, что с увеличением зазора растёт расход жидкости при падении подачи воздуха. Кроме того, увеличивается значение потребляемой мощности. Как следствие, увеличение величины межцилиндрового зазора в данной установке с точки зрения аэрирования не является целесообразным.

\section{Выводы}

На основании экспериментальных данных были получены соотношения гидродинамических величин при обработке питательных сред для культивирования дрожжей в ферментёре, paботающем по принципу дискретно-импульсного ввода энергии. Исследовано влияние подачи воздуха на гидродинамические показатели работы роторно-пульсационного аппарата. Полученные зависимости могут быть использовании при выборе режимов культивирования, а также при проектировании ферментёров на базе роторно-пульсационных аппаратов.

\section{ЛИТЕРАТУРА}

1. Экологическая биотехнология /Под ред. К.Ф. Форстера, Д. А. Дж. Вейза. - Л.: Химия 1990. - 384 c.

2. Промышленная микробиология: Учеб. Пособие для вузов по спец. "Микробиология" и "Биология"/ [ 3.А. Аркадьева, А.М. Безбородов, И.Н. Блохина и др.]; под ред. Н.С. Егорова. - М. Высш. шк., 1989. - 688 с.

3. Новаковская С.С. Справочник по производству хлебопекарских дрожжей/ С.С. Новаковская, Ю.И. Шишацкий. - М. .: Пищевая промышленность , $1980-374$ с.

4. Ободович A. Н. Устройство для оптимизации массообменных процессов за счёт дискретно-импульсного ввода энергии при культивировании микроорганизмов / А.Н. Ободович, С.И. Костик, В.В. Сидоренко // Енергетика : економіка, технології, екологія. - 2014. - № 4. - С. 23 - 26.

5. Башта T.M. Гидравлика, гидромашины и гидроприводы: Учебник для машиностроительных вузов / Т.М. Башта, С.С. Руднев, Б.Б. Некрасов [и др.]- 2-е изд., перераб.- М.: Машиностроение, 1982. $-423 \mathrm{c}$. 
PECULARITIES OF HYDRODYNAMIC PROCESSING OF THE NUTRIENT MEDIUM IN THE ROTOR-PULSATION APPARATUS

\section{Obodovich A.N. ${ }^{1}$, Mudrak T. O. $^{2}$, Sidorenko V.V. ${ }^{1}$}

${ }^{1}$ Institute of Engineering Thermophysics, National Academy of Sciences of Ukraine, Zhelyabova str., 2a, Kiev, 03680, Ukraine

${ }^{2}$ National University of Food Technologies, Volodymyrskaya str., 68, Kiev, 01601, Ukraine

The paper presents the obtained on the basis of experimental data, the ratio of the flow variables in the processing of culture media for culturing yeast in a fermenter, works on the principle of discreteinput pulse energy. The influence of the air on the hydrodynamic performance of the rotor-pulsation apparatus is investigated. Obtained results can be used for selecting the mode of cultivation as well as for the design fermenters based on rotary-pulsation apparatus.

References 5, fig. 7 .
Key words: aeration, rate, pressure, power consumption, rotary - pulsation apparatus

1. Environmental biotechnology / by edition C.F. Forster and D.A. John Wase. - L.: Himiya 1990. - 384 p. (Rus)

2. Industrial microbiology / [Z.A. Arkadeva, A.M. Bezborodov, I.N. Blohina at al.]; by edition N.S. Egorov. - M.: Vyissh. shk., 1989. - 688 p. (Rus)

3. Novakovskaya S.S. Handbook for the production of bakery yeast/S.S. Novakovskaya, U.I. Shishatsky. - M.: Pishevaya promyshlennost, 1980 374 p. (Rus)

4. Obodovich A.N. Device to optimize mass transfer processes at the expense of discrete pulse energy input during cultivation of microorganisms/ A.N. Obodovich, S.I. Kostik, V.V. Sidorenko// Energetika: ekonomika, tehnollogii, ekologiya. 2014. - № 4. - p. 23 - 26 (Rus)

5. Bashta T.M. Hydraulics, hydraulic machines and hydraulic drives: A textbook for engineering universities/ T.M. Bashta, S.S. Rudnev, B.B. Nekrasov [et al]. - 2d ed., .- M.: Mashinostroenie, 1982. - 423p. (Rus) 